\title{
Effectiveness and safety of repeat dexamethasone for bronchopulmonary dysplasia
}

\author{
Alain Cuna ${ }^{1,2,3} \cdot$ Anastasia Quiqley $^{4} \cdot K^{2}$ vin Varghese ${ }^{2} \cdot$ Greta Ciccolari-Micaldi $^{4} \cdot$ Christian Oliveros $^{5}$. \\ An-Lin Cheng ${ }^{2} \cdot$ Michael Norberg $^{1,3} \cdot$ William E. Truog ${ }^{1,2,3}$
}

Received: 7 January 2021 / Revised: 14 May 2021 / Accepted: 27 May 2021 / Published online: 8 June 2021

(c) The Author(s), under exclusive licence to Springer Nature America, Inc. 2021

\begin{abstract}
Objective: To describe effectiveness of repeat dexamethasone for bronchopulmonary dysplasia (BPD) and to evaluate adverse effects on growth.

Study design: Retrospective study of infants treated with 1 or 2 courses of dexamethasone for BPD. Effectiveness was defined as successful step-down in respiratory support by end of treatment. Adverse effects on growth were analyzed and compared to untreated controls.

Results: A total of 132 dexamethasone-treated infants were identified. In total, 52\% (69/132) of infants treated with initial dexamethasone achieved step-down in respiratory support compared to $38 \%$ (20/52) of infants with repeat dexamethasone. Growth trajectory did not significantly differ among infants treated with 1 or 2 courses of dexamethasone compared with controls (weight: $P=0.23$, length: $P=0.68$, and head circumference: $P=0.77$ ).

Conclusions: Repeat dexamethasone for BPD was less effective in weaning respiratory support compared to initial course. Changes in growth parameters to discharge were comparable between controls and infants treated with 1 or 2 dexamethasone courses.
\end{abstract}

\section{Introduction}

Preterm infants who remain ventilator-dependent for 2 or more weeks are at high risk for developing bronchopulmonary dysplasia (BPD)-a form of chronic lung disease of prematurity with significant morbidity and mortality [1,2]. Postnatal steroids (PNS) such as dexamethasone are powerful antiinflammatory agents that have been shown to improve lung

Alain Cuna

accuna@cmh.edu

1 Division of Neonatology, Children's Mercy Kansas City, Kansas City, MO, USA

2 School of Medicine, University of Missouri-Kansas City, Kansas City, MO, USA

3 Center for Infant Pulmonary Disorders, Children's Mercy Kansas City, Kansas City, MO, USA

4 School of Medicine, University of Kansas Medical Center, Kansas City, KS, USA

5 Department of Pediatrics, Children's Mercy Kansas City, Kansas City, MO, USA function, facilitate extubation, and decrease rates of BPD [3-6]. While the routine use of PNS in preterm infants is not advised because of harmful effects to the developing brain [7-9], a selective approach has been recommended that limits treatment to high-risk infants who remain chronically ventilated [10]. Meta-regression analysis of randomized trials indicates that such a targeted approach shifts the risk-benefit profile of PNS toward more benefit $[11,12]$.

The effectiveness of a single course of PNS to improve lung function and facilitate extubation can vary widely. Data from randomized controlled trials indicate that as many as $24 \%$ to $53 \%$ of treated infants fail to extubate following the first course of steroids [13-19]. In some of these trials, treatment with a repeat or rescue course of open-label steroids for study infants who remain chronically intubated has been described. The safety and effectiveness of repeat courses of PNS, however, have not been adequately defined.

In our practice, infants who failed to extubate after the first course of PNS are often considered for a repeat course if their lung disease remains substantial (i.e., unable to wean from mechanical ventilation or high non-invasive ventilation settings). In this study, we aimed to describe the rate of successful step-down in respiratory support (i.e., invasive ventilation to 
Table 1 Baseline demographics and clinical outcomes of the study population.

\begin{tabular}{|c|c|c|c|c|c|}
\hline & \multirow[t]{2}{*}{$\begin{array}{l}\text { Controls } \\
N=147\end{array}$} & \multirow{2}{*}{$\begin{array}{l}\text { Steroid } \\
\text { treated } \\
N=132\end{array}$} & \multicolumn{3}{|c|}{$\begin{array}{l}\text { Comparison of steroid-treated } \\
\text { infants }\end{array}$} \\
\hline & & & $\begin{array}{l}1 \text { course } \\
N=80\end{array}$ & $\begin{array}{l}2 \text { courses } \\
N=52\end{array}$ & $P$ value \\
\hline Gestational age, weeks & $26.8 \pm 1.9$ & $25.2 \pm 1.6$ & $25.1 \pm 1.3$ & $25.4 \pm 2.0$ & 0.38 \\
\hline Birth weight, grams & $\begin{array}{l}946.0 \pm \\
270.6\end{array}$ & $726.8 \pm 190.6$ & $\begin{array}{l}737.6 \pm \\
186.2\end{array}$ & $\begin{array}{l}710.3 \pm \\
198.0\end{array}$ & 0.42 \\
\hline Male sex & $76(52)$ & $92(70)$ & $54(68)$ & $38(73)$ & 0.50 \\
\hline Race $^{\mathrm{a}}$ & & & & & 0.35 \\
\hline White & $77(52)$ & $58(44)$ & $37(46)$ & $21(40)$ & \\
\hline Black & $40(27)$ & $50(38)$ & $32(40)$ & $18(35)$ & \\
\hline Hispanic & $19(13)$ & $12(9)$ & $6(8)$ & $6(12)$ & \\
\hline Small for gestational age & $14(10)$ & 24 (18) & $10(13)$ & $14(27)$ & 0.04 \\
\hline Apgar $\leq 5$ at $1 \min ^{\mathrm{b}}$ & $106(72)$ & $114(86)$ & $73(91)$ & $41(79)$ & 0.12 \\
\hline Apgar $\leq 5$ at $5 \min ^{\mathrm{b}}$ & $59(40)$ & $54(41)$ & $35(44)$ & $19(37)$ & 0.50 \\
\hline Twin gestation & $44(30)$ & $34(26)$ & $15(19)$ & $19(37)$ & 0.02 \\
\hline Caesarian delivery & $102(69)$ & $96(73)$ & $57(71)$ & $39(75)$ & 0.63 \\
\hline Use of antenatal steroids ${ }^{c}$ & $112(76)$ & $101(77)$ & $58(73)$ & $43(83)$ & 0.34 \\
\hline Surfactant therapy & $141(96)$ & $128(97)$ & 79 (99) & $49(94)$ & 0.14 \\
\hline \multicolumn{6}{|l|}{ Outcomes $^{\mathrm{d}}$} \\
\hline Death & $3(2)$ & $12(9)$ & $6(8)$ & $6(12)$ & 0.54 \\
\hline Severe BPD & $58(40)$ & $93(78)$ & $55(74)$ & $38(83)$ & 0.02 \\
\hline Culture-proven sepsis & $36(25)$ & $58(48)$ & $35(47)$ & $23(50)$ & 0.85 \\
\hline $\begin{array}{l}\text { Medical or surgical necrotizing } \\
\text { enterocolitis }\end{array}$ & $25(17)$ & $19(16)$ & $12(16)$ & $7(15)$ & 1.0 \\
\hline Patent ductus arteriosus ligation & $26(18)$ & $32(27)$ & $16(22)$ & $16(35)$ & 0.14 \\
\hline $\begin{array}{l}\text { Periventricular leukomalacia or } \\
\text { severe intraventricular hemorrhage } \\
\text { (grade } 3 \text { or } 4 \text { ) }\end{array}$ & $45(31)$ & $41(34)$ & $29(39)$ & $12(26)$ & 0.23 \\
\hline $\begin{array}{l}\text { Retinopathy of prematurity } \\
\text { requiring treatment }\end{array}$ & $25(17)$ & $30(25)$ & $20(27)$ & $10(22)$ & 0.67 \\
\hline Tracheostomy & $5(3)$ & $13(11)$ & $2(3)$ & $11(24)$ & $<0.001$ \\
\hline Gastrostomy tube & $28(19)$ & $48(40)$ & $22(30)$ & $26(57)$ & 0.004 \\
\hline Length of stay, days & $100.8 \pm 33.5$ & $162.6 \pm 87.6$ & $\begin{array}{l}149.0 \pm \\
98.9\end{array}$ & $\begin{array}{l}184.6 \pm \\
60.3\end{array}$ & 0.03 \\
\hline
\end{tabular}

Data are presented as means \pm standard deviation or counts (percentages).

${ }^{\mathrm{a}} 11$ infants did not have data on maternal race.

${ }^{\text {b}} 7$ infants did not have data on Apgar scores.

${ }^{\mathrm{c}} 1$ infant did not have data on antenatal steroid.

${ }^{\mathrm{d}}$ Because death is a competing outcome, the 12 infants who died were excluded from the analysis of other clinical outcomes. non-invasive ventilation, non-invasive ventilation to nasal cannula) after treatment with first and second courses of PNS for BPD and explore potential adverse effects of repeat PNS treatment on growth.

\section{Subjects and methods}

This 10-year retrospective cohort study was conducted in the regional level IV neonatal intensive care unit at Children's
Mercy Kansas City (CMKC) in Kansas City, MO, between January 2010 and December 2019. De-identified data for the study were obtained from the Infant Pulmonary Data Repository of the Center for Infant Pulmonary Disorders at CMKC with approval by the local Institutional Review Board.

\section{Study population}

We included preterm infants born at $<30$ weeks gestation who received treatment with 1 or 2 courses of PNS for BPD in the 
Fig. 1 Flowchart showing outcomes of infants treated with dexamethasone. Overall effectiveness of dexamethasone to wean respiratory support decreased from $52 \%(69 / 132)$ with initial treatment to $38 \%$ (20/52) with repeat treatment. Comparing only infants on mechanical ventilation, the proportion of infants extubated decreased from $52 \%$ with the first course to $35 \%$ with the second course of dexamethasone. $\mathrm{NC}$ nasal cannula, NIV non-invasive ventilation, PNS postnatal steroids.

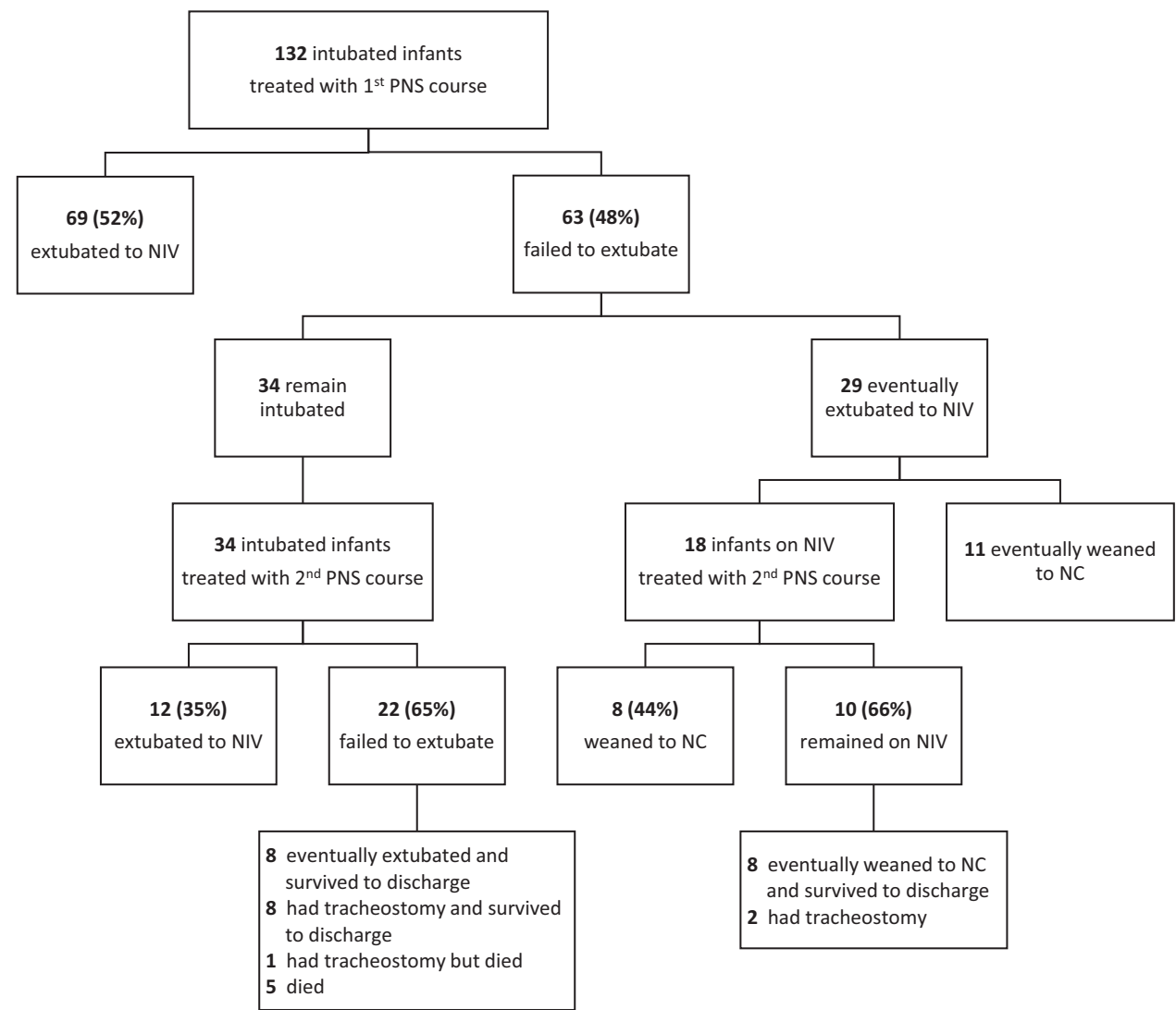

study. A cohort of infants $<30$ weeks of gestation who did not receive PNS treatment for BPD during their clinical course served as controls. Infants who received additional systemic steroids for reasons other than BPD-such as for adrenal insufficiency or for airway edema-remained eligible for inclusion.

\section{Use of PNS for BPD}

During the study period, the decision to treat preterm infants with PNS for evolving BPD was at the discretion of the neonatologist. Our general practice is to limit the use of PNS to preterm infants at high risk for developing BPD as per the most recent recommendations by the American Academy of Pediatrics [10]. Typically, preterm infants selected for their first course of PNS treatment included those who remain on invasive ventilation for more than 2 weeks of life on moderate to high ventilator settings. A standardized dosing regimen of lowdose dexamethasone $(0.89 \mathrm{mg} / \mathrm{kg}$ weaned over 10 days as per Dexamethasone: A Randomized Trial or a modified regimen of $0.72 \mathrm{mg} / \mathrm{kg}$ weaned over 7 days) was used whenever the decision is made to treat with PNS [19, 20]. In selected cases, the second course of PNS may be considered at the discretion of the treating neonatologist for infants who remained on invasive ventilation despite first steroid treatment or who were in high non-invasive ventilation settings.

\section{Outcomes and variables}

The primary outcome was rate of successful step-down in respiratory support (i.e. invasive ventilation to non-invasive ventilation; non-invasive ventilation to nasal cannula) at the end of PNS treatment. Our secondary outcome was growth trajectory in the NICU, which was assessed by comparing birth and discharge weight, length, and head circumference $z$-scores as calculated using the Fenton 2013 Preterm Growth Chart for infants with postmenstrual age (PMA) < 50 weeks and the World Health Organization Growth Standard for infants $\geq 50$ weeks PMA [21, 22]. Data were also collected on maternal and infant demographics, baseline clinical characteristics at the start of PNS treatment, and major clinical outcomes including death, severe BPD defined as oxygen need $\geq 30 \%$ or positive pressure ventilation at 36 PMA [23], sepsis, necrotizing enterocolitis, severe intraventricular hemorrhage, periventricular leukomalacia, retinopathy of prematurity requiring treatment, tracheostomy, gastrostomy tube placement, and length of stay.

\section{Statistical analysis}

Descriptive statistics such as mean and standard deviations, median and interquartile ranges, and proportions were used 
Table 2 Characteristics of intubated infants at time of treatment with first or second course of dexamethasone.

\begin{tabular}{|c|c|c|c|c|c|c|}
\hline & \multicolumn{3}{|c|}{ First dexamethasone course } & \multicolumn{3}{|c|}{ Second dexamethasone course } \\
\hline & $\begin{array}{l}\text { Successfully } \\
\text { extubated } \\
(N=69)\end{array}$ & $\begin{array}{l}\text { Not } \\
\text { successfully } \\
\text { extubated } \\
(N=63)\end{array}$ & $P$ value & $\begin{array}{l}\text { Successfully } \\
\text { extubated } \\
(N=12)\end{array}$ & $\begin{array}{l}\text { Not } \\
\text { successfully } \\
\text { extubated } \\
(N=22)\end{array}$ & $P$ value \\
\hline Age at treatment, days & $37.5 \pm 17.4$ & $35.8 \pm 19.0$ & 0.59 & $70.8 \pm 25.4$ & $73.2 \pm 26.0$ & 0.80 \\
\hline PMA at treatment, weeks & $30.6 \pm 2.7$ & $30.2 \pm 3.5$ & 0.45 & $34.7 \pm 3.8$ & $36.7 \pm 4.8$ & 0.20 \\
\hline Dexamethasone course & & & 1.0 & & & 1.0 \\
\hline 7 days & $34(49)$ & $31(49)$ & & $6(50)$ & $10(45)$ & \\
\hline 10 days & $35(51)$ & $32(51)$ & & $6(50)$ & $12(55)$ & \\
\hline Respiratory support & & & $<0.001$ & & & 0.44 \\
\hline HFOV & $26(38)$ & $47(75)$ & & $6(50)$ & $8(36)$ & \\
\hline $\mathrm{CV}$ & $43(62)$ & $16(25)$ & & $6(50)$ & $14(64)$ & \\
\hline MAP & $11.7 \pm 2.7$ & $13.7 \pm 2.5$ & $<0.001$ & $13.5 \pm 2.1$ & $15.0 \pm 3.3$ & 0.20 \\
\hline $\mathrm{FiO}_{2}$ & $58.5 \pm 19.4$ & $70.7 \pm 17.8$ & $<0.001$ & $57.8 \pm 19.3$ & $65.6 \pm 16.8$ & 0.23 \\
\hline $\mathrm{PCO}_{2}{ }^{\mathrm{a}}$ & $69.8 \pm 113.7$ & $70.6 \pm 105.9$ & 0.97 & $57.7 \pm 5.8$ & $58.1 \pm 9.0$ & 0.88 \\
\hline RSS & $6.98 \pm 3.1$ & $9.6 \pm 3.5$ & $<0.001$ & $7.8 \pm 3.2$ & $10.1 \pm 3.6$ & 0.09 \\
\hline
\end{tabular}

Data are presented as means \pm standard deviation or counts (percentages).

$\mathrm{CV}$ conventional ventilation, $\mathrm{FiO} 2$ fraction of inspired oxygen, $\mathrm{HFOV}$ high frequency oscillatory ventilation, $M A P$ mean airway pressure, $\mathrm{PCO}_{2}$ partial pressure of carbon dioxide, $\mathrm{RSS}$ respiratory severity score (MAP x $\mathrm{FiO} 2)$

${ }^{a} \mathrm{PCO} 2$ values presented reflect mixed sampling (arterial, venous, and capillary). to summarize the data. Differences between groups on outcome variables were analyzed by using chi-square test, Student's $t$-test, or analysis of variance (ANOVA) with Bonferroni correction as appropriate. Mixed model repeated measures ANOVA was used to determine differences in growth parameters from birth to discharge among control infants and infants treated with 1 or 2 courses of PNS. Multiple logistic regression modeling was used to examine the impact of potential confounders on the association between PNS treatment and successful extubation. All statistical tests were two-sided, with a $P$ value of $<0.05$ deemed significant. Statistical analysis was performed using SPSS software, version 24 (IBM Corp, Armonk, NY).

\section{Results}

We identified 132 preterm infants treated with dexamethasone for BPD and 147 untreated infants as controls. Steroid-treated infants had mean gestational age of $25.2 \pm 1.6$ weeks and mean birth weight of $727 \pm 191$ grams. The majority of the treated cohort were of male gender and White race. Other baseline demographic data are presented in Table 1. Overall, infants who received one versus 2 courses of dexamethasone for BPD had similar baseline demographics including gestational age and birth weight. Small for gestational age status and twin gestation were more common among infants treated with 2 dexamethasone courses. Clinical outcomes were comparable between the two groups except for rates of severe BPD, tracheostomy, and gastrostomy tube which were higher among infants treated with repeat dexamethasone (Table 1).

The overall rate of successful step-down in respiratory support after an initial course of dexamethasone was 52\% (69 of 132 infants, Fig. 1). The median age in days and median PMA in weeks at time of initial dexamethasone treatment were 32 days (interquartile range 25 to 42 days) and 29.8 weeks (interquartile range 28.4-31.6 weeks), respectively. The characteristics of infants who successfully weaned from invasive to non-invasive ventilation at the time of initial treatment with dexamethasone are shown in Table 2. Successful step-down was significantly higher in infants with lower levels of respiratory support as determined by type of invasive ventilation (conventional vs high frequency), mean airway pressure, fraction of inspired oxygen, and respiratory severity score (RSS, which is mean airway pressure $x$ fraction of inspired oxygen). Logistic regression analysis adjusting for birth weight, sex, antenatal steroids, and age and respiratory support at time of treatment identified that successful step-down to noninvasive ventilation was independently associated with conventional ventilation (adjusted odds ratio [aOR] 3.4, 95\% confidence interval $[\mathrm{CI}] 1.2-10.0, P=0.02$ ) and lower RSS (aOR $0.83,95 \%$ CI $0.72-0.97, P=0.02$ ).

Fifty-two of the study infants received a repeat course of dexamethasone because of progressive lung disease and inability to wean from prolonged respiratory support (Fig. 1). Of these, 34 infants were on mechanical ventilation, while the remaining 18 infants were on non-invasive ventilatory support. The median age in days and PMA in weeks at time of repeat 
Table 3 Growth parameters of the study population.

\begin{tabular}{llllll}
\hline Growth parameter $z$-scores & Control & 1 course & 2 courses & $P$ value & \\
\cline { 4 - 6 } & & & Control vs 1 course & Control vs 2 courses 1 vs 2 courses \\
\hline Weight & & & & 0.004 & 0.45 \\
$\quad$ Birth & $-0.22 \pm 0.08$ & $-0.05 \pm 0.11$ & $-0.31 \pm 0.16$ & 0.15 & 0.12 \\
$\quad$ Discharge & $-1.34 \pm 0.10$ & $-1.26 \pm 0.11$ & $-1.74 \pm 0.20$ & 1.0 & $<0.001$ \\
Length & & & & & $<0.001$ \\
$\quad$ Birth & $-0.07 \pm 0.09$ & $-0.39 \pm 0.14$ & $-0.71 \pm 0.21$ & 0.02 & 0.45 \\
$\quad$ Discharge & $-1.41 \pm 0.12$ & $-1.72 \pm 0.15$ & $-2.34 \pm 0.22$ & 0.38 & 0.06 \\
Head circumference & & & & & 0.008 \\
$\quad$ Birth & $0.06 \pm 0.09$ & $-0.22 \pm 0.12$ & $-0.49 \pm 0.18$ & 0.22 & 0.06 \\
$\quad$ Discharge & $-0.82 \pm 0.10$ & $-0.93 \pm 0.13$ & $-1.35 \pm 0.27$ & 1.0 & 0.30 \\
\hline
\end{tabular}

Values indicate mean \pm standard error of the mean. $P$ values were calculated using ANOVA with Bonferroni correction for multiple comparisons.
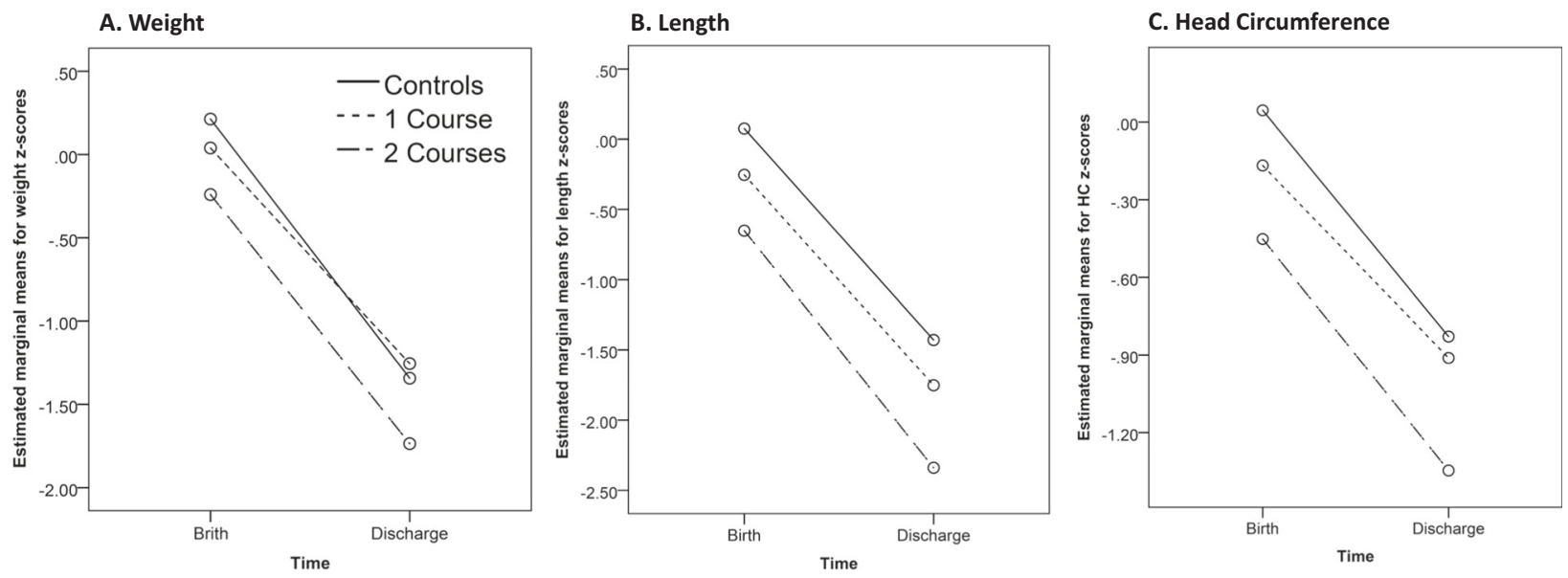

Fig. 2 Changes in growth parameters from birth to discharge. Infants treated with 2 courses of dexamethasone had significantly lower mean z-scores for weight, length, and head circumference over time compared to untreated controls. No significant time $x$ group interactions were observed in weight, length, and head circumference, indicating a comparable downward trajectory in growth parameters between the different groups. Weight, length, and head circumference $z$-scores were calculated using the Fenton 2013 Growth Calculator for Preterm Infants or the World Health Organization Growth Standard. dexamethasone treatment were 66 days (interquartile range 53-84 days) and 35.3 weeks (interquartile range 32.9-37.8 weeks), respectively. Overall effectiveness of repeat dexamethasone treatment to facilitate step-down in respiratory support was $38 \%$ (20 of 52 infants, Fig. 1). Comparing only infants on mechanical ventilation, the proportion of infants successfully extubated with dexamethasone treatment decreased from $52 \%$ with the first course to $35 \%$ with the second course.

The potential safety of repeat dexamethasone therapy was assessed by analyzing differences in growth parameters of infants treated with 1 or 2 courses of dexamethasone with those of a cohort of untreated controls. One-way ANOVA with Bonferroni correction for multiple comparisons showed that infants treated with 2 courses of dexamethasone had lower mean $z$-scores for weight, length, and head circumference at birth compared to untreated infants (Table 3). A lower mean $z$-score for length at birth was also observed among infants treated with one course of dexamethasone compared to untreated controls. At discharge, infants treated with 2 courses of dexamethasone continued to demonstrate lower mean $z$-scores for length compared to untreated controls; but mean $z$-scores for weight and head circumference were no longer different. No statistically significant differences in growth parameters at birth or at discharge were observed between infants treated with 1 or 2 courses of dexamethasone (Table 3).

Mixed-model repeated-measures analysis was then used to determine differences in growth parameters over time between the different cohorts. Compared to the untreated control group, infants treated with 2 courses of dexamethasone had lower $z$-scores for weight, length, and head circumference at birth and at discharge (Fig. 2). Lower $z$-scores for weight and length were also observed in infants treated with 2 dexamethasone courses compared to infants treated with just a single course 
(Fig. 2). However, no significant interaction was noted between time and the different groups in relation to weight $(P=0.23)$, length $(P=0.68)$, or head circumference $(P=0.77)$, indicating comparable growth trajectory across the different cohorts (Fig. 2).

\section{Discussion}

In this study, we found that repeat PNS treatment for BPD had decreased effectiveness in facilitating weaning from respiratory support compared to initial steroid treatment. Infants treated with repeat steroids had lower weight, length, and head circumference at birth but a similar growth trajectory in the NICU as untreated infants. These results suggest that while repeat PNS treatment is less effective compared to the initial course, there seems to be no indication of statistically significant effects of repeat PNS treatment on growth trajectory to discharge.

In the majority of the randomized trials of steroids for BPD, the allowance for rescue open-label steroid treatment in all participants meant that a small subset of infants randomized to receive the active drug received a second course of PNS. Outcome data on how these infants fared have not been widely reported. Therefore, there is a paucity of evidence on the safety and effectiveness of repeat steroid treatment for BPD. How often repeat steroid treatment is used for infants who remain on high levels of respiratory support is also unknown. In our study, 34 of $132(26 \%)$ steroid-treated infants received a second course of dexamethasone while on mechanical ventilation. This rate of repeat PNS treatment is similar to the 10 of 35 (29\%) infants in the Dexamethasone: A Randomized Trial study who were randomized to dexamethasone and received an open-label second course of dexamethasone [19]. However, including both intubated and non-intubated infants, the rate of repeat dexamethasone treatment in our study increases to $39 \%$ (52 of 132).

A smaller study by Dassios et al. [24] also retrospectively reviewed their 10-year single-center experience regarding repeat systemic dexamethasone treatment for BPD. Their study had a lower rate of repeat PNS treatment at $19 \%$ (15 of 81 steroid-treated infants) and a much higher rate of successful extubation at $93 \%$ (14 of 15 infants). In comparing the two studies, the cohort of infants who received repeat PNS treatment in our study was slightly more premature, had lower birth weights, and was treated at a later chronological age and at a higher level of respiratory support. Our study also used a much smaller cumulative dexamethasone dose (0.72-0.89 $\mathrm{mg} / \mathrm{kg}$ over $7-10$ days), as compared to their regimen $(2.7 \mathrm{mg} / \mathrm{kg}$ over 9 days $)$. While the exact reasons are unclear, it is possible that the subtle differences between the two cohorts, as well as the larger difference in dexamethasone dose, contribute to the differences in rate of repeat PNS treatment and effectiveness in facilitating extubation.

Among the safety concerns of repeated courses of systemic dexamethasone for BPD is a detrimental effect on growth [25, 26]. In our study, infants who received 2 PNS courses had significantly lower growth parameters at birth compared to untreated infants, suggesting that poor growth in-utero may be an important predictor for subsequent respiratory morbidity and need for repeated corticosteroid treatment. While length at discharge remained significantly lower among infants with 2 PNS courses compared to controls, both weight and head circumference were no longer statistically different. This observation suggests that although some catch-up growth in weight and head circumference is possible, catch-up growth in length appears more challenging. Interestingly, untreated control infants also had decreased growth parameters from birth to discharge, and repeated measures analysis demonstrated a comparable trend of poor growth between untreated infants and infants with 1 or 2 PNS courses. An important limitation of our analysis is that discharge growth parameters were not analyzed at a similar PMA because of the variation in age at discharge among untreated infants and infants treated with one or two PNS courses. Nevertheless, our finding of poor growth across all the three different cohorts underscores the problem of extrauterine growth restriction, stresses the clinical importance of focusing on nutrition, and highlights the need for further research on optimal nutrition of very preterm infants [27, 28].

Our study describes the largest cohort to date of preterm infants treated with repeat dexamethasone for BPD and is the first to provide data on potential safety effects on growth. Because repeat steroid treatment for BPD is an infrequent therapy, our study remains limited by relatively small sample size. Its retrospective design also precludes us from identifying the precise clinical rationale for repeat dexamethasone treatment. Our study is also limited by the availability of information from our local data repository, which did not have data on important confounding factors such as steroid treatment for airway edema or adrenal insufficiency. Our single-center experience at a tertiary referral center may also not be generalizable to other centers, as our cohorts of steroid-treated and steroid-naïve controls are mostly comprised of infants referred from other hospitals.

In conclusion, the second course of low-dose dexamethasone for BPD in ventilator-dependent preterm infants can help improve lung function in some patients. While overall effectiveness in facilitating weaning of respiratory support is lower compared to the initial steroid course, growth does not seem to be adversely affected. Larger retrospective studies that combine data from several centers and well-designed prospective studies are needed to further evaluate the safety and efficacy of repeat steroid treatment for BPD. 
Acknowledgements We thank the Medical Writing Center at Children's Mercy Kansas City for help with editing and proofreading this manuscript.

Funding information $\mathrm{AC}$ is supported in part by the National Institute of Health [K08DK125735]. KV received funding for statistical support from the University of Missouri-Kansas City Sarah Morrison Student Research Award.

Author contributions AC conceptualized and designed the study, carried out the initial analysis, drafted the initial manuscript, and supervised all aspects of the study. AQ, KV, GC-M, and CO collected the data, performed preliminary analysis on the data, and reviewed and revised the manuscript. A-LC carried out the statistical analysis and reviewed and revised the manuscript. MN designed the data collection repository, coordinated and supervised data collection, and reviewed and revised the manuscript. WET contributed to the conceptualization and design the study, and critically reviewed the manuscript for important intellectual content. All authors approved the final manuscript as submitted and agree to be accountable for all aspects of the work.

Conflict of interest The authors declare no competing interests.

Publisher's note Springer Nature remains neutral with regard to jurisdictional claims in published maps and institutional affiliations.

\section{References}

1. Bancalari E, Claure N, Sosenko IR. Bronchopulmonary dysplasia: changes in pathogenesis, epidemiology and definition. Semin neonatology: SN. 2003;8:63-71.

2. Walsh MC, Morris BH, Wrage LA, Vohr BR, Poole WK, Tyson $\mathrm{JE}$, et al. Extremely low birthweight neonates with protracted ventilation: mortality and 18-month neurodevelopmental outcomes. J pediatrics. 2005;146:798-804.

3. Doyle LW, Cheong JLY. Postnatal corticosteroids to prevent or treat bronchopulmonary dysplasia-Who might benefit? Semin fetal neonatal Med. 2017;22:290-5.

4. Eichenwald EC, Stark AR. Are postnatal steroids ever justified to treat severe bronchopulmonary dysplasia? Arch Dis Child Fetal neonatal Ed. 2007;92:F334-337.

5. Halliday HL. Update on postnatal steroids. Neonatology. 2017;111:415-22.

6. Jobe AH. Postnatal corticosteroids for bronchopulmonary dysplasia. Clin Perinatol. 2009;36:177-88.

7. Barrington KJ. The adverse neuro-developmental effects of postnatal steroids in the preterm infant: a systematic review of RCTs. BMC pediatrics. 2001;1:1.

8. Cheong JL, Anderson P, Roberts G, Duff J, Doyle LW.Victorian Infant Collaborative Study G Postnatal corticosteroids and neurodevelopmental outcomes in extremely low birthweight or extremely preterm infants: 15-year experience in Victoria. Aust Arch Dis Child Fetal neonatal Ed. 2013;98:F32-36.

9. Wilson-Costello D, Walsh MC, Langer JC, Guillet R, Laptook AR, Stoll BJ, et al. Impact of postnatal corticosteroid use on neurodevelopment at 18 to 22 months' adjusted age: effects of dose, timing, and risk of bronchopulmonary dysplasia in extremely low birth weight infants. Pediatrics. 2009;123:e430-437.

10. Watterberg KL.American Academy of Pediatrics. Committee on F, Newborn Policy statement-postnatal corticosteroids to prevent or treat bronchopulmonary dysplasia. Pediatrics. 2010;126:800-8.
11. Doyle LW, Halliday HL, Ehrenkranz RA, Davis PG, Sinclair JC. Impact of postnatal systemic corticosteroids on mortality and cerebral palsy in preterm infants: effect modification by risk for chronic lung disease. Pediatrics. 2005;115:655-61.

12. Doyle LW, Halliday HL, Ehrenkranz RA, Davis PG, Sinclair JC. An update on the impact of postnatal systemic corticosteroids on mortality and cerebral palsy in preterm infants: effect modification by risk of bronchopulmonary dysplasia. J pediatrics. 2014;165:1258-60.

13. Yeh TF, Lin YJ, Hsieh WS, Lin HC, Lin CH, Chen JY, et al. Early postnatal dexamethasone therapy for the prevention of chronic lung disease in preterm infants with respiratory distress syndrome: a multicenter clinical trial. Pediatrics. 1997;100:E3.

14. Kari MA, Heinonen K, Ikonen RS, Koivisto M, Raivio KO. Dexamethasone treatment in preterm infants at risk for bronchopulmonary dysplasia. Arch Dis Child. 1993;68:566-9. (5 Spec No)

15. Kazzi NJ, Brans YW, Poland RL. Dexamethasone effects on the hospital course of infants with bronchopulmonary dysplasia who are dependent on artificial ventilation. Pediatrics. 1990;86:722-7.

16. Shinwell ES, Karplus M, Zmora E, Reich D, Rothschild A, Blazer $S$, et al. Failure of early postnatal dexamethasone to prevent chronic lung disease in infants with respiratory distress syndrome. Arch Dis Child Fetal neonatal Ed. 1996;74:F33-37.

17. Garland JS, Alex CP, Pauly TH, Whitehead VL, Brand J, Winston $\mathrm{JF}$, et al. A three-day course of dexamethasone therapy to prevent chronic lung disease in ventilated neonates: a randomized trial. Pediatrics. 1999;104:91-99.

18. Rastogi A, Akintorin SM, Bez ML, Morales P, Pildes RS. A controlled trial of dexamethasone to prevent bronchopulmonary dysplasia in surfactant-treated infants. Pediatrics. 1996;98:204-10.

19. Doyle LW, Davis PG, Morley CJ, McPhee A, Carlin JB, Investigators DS. Low-dose dexamethasone facilitates extubation among chronically ventilator-dependent infants: a multicenter, international, randomized, controlled trial. Pediatrics. 2006;117:75-83.

20. Cuna A, Govindarajan S, Oschman A, Dai H, Brophy K, Norberg $\mathrm{M}$, et al. A comparison of 7-day versus 10-day course of low-dose dexamethasone for chronically ventilated preterm infants. J Perinatol. 2017;37:301-5.

21. Fenton TR, Kim JH. A systematic review and meta-analysis to revise the Fenton growth chart for preterm infants. BMC pediatrics. 2013;13:59.

22. de Onis M, Garza C, Victora CG, Onyango AW, Frongillo EA, Martines J. The WHO multicentre growth reference study: planning, study design, and methodology. Food Nutr Bull. 2004;25: S15-26.

23. Jobe AH, Bancalari E. Bronchopulmonary dysplasia. Am J respiratory Crit care Med. 2001;163:1723-9.

24. Dassios T, Kaltsogianni O, Greenough. A second course of systemic dexamethasone: efficacy and respiratory function changes. J Matern Fetal Neonatal Med. 2020:1-4.

25. Bloomfield FH, Knight DB, Harding JE. Side effects of 2 different dexamethasone courses for preterm infants at risk of chronic lung disease: a randomized trial. J pediatrics. 1998;133:395-400.

26. Linafelter A, Cuna A, Liu C, Quigley A, Truog WE, Sampath V, et al. Extended course of prednisolone in infants with severe bronchopulmonary dysplasia. Early Hum Dev. 2019;136:1-6.

27. Goldberg DL, Becker PJ, Brigham K, Carlson S, Fleck L, Gollins L, et al. Identifying malnutrition in preterm and neonatal populations: recommended indicators. J Acad Nutr Diet. 2018;118:1571-82.

28. Fenton TR, Griffin IJ, Groh-Wargo S, Gura K, Martin CR, Taylor SN, et al. Very low birthweight preterm infants: a 2020 evidence analysis center evidence-based nutrition practice guideline. J Acad Nutr Diet. 2021;S2212-267:200149-0. 